\title{
Relaparotomy after caesarean section: an analysis of the risk factors, indications and outcome
}

\author{
Naseema Beevi Ahmed Khan*, Smitha Sreenivas Kolasseri
}

Department of Obstetrics \& Gynaecology, Government Medical College, Kozhikode, Kerala, India

Received: 23 February 2015

Revised: 28 February 2015

Accepted: 19 April 2015

\section{*Correspondence:}

Dr. Naseema Beevi Ahmed Khan,

E-mail: anaseemabeevi@yahoo.com

Copyright: (C) the author(s), publisher and licensee Medip Academy. This is an open-access article distributed under the terms of the Creative Commons Attribution Non-Commercial License, which permits unrestricted non-commercial use, distribution, and reproduction in any medium, provided the original work is properly cited.

\section{ABSTRACT}

Background: Aim of this study was to establish the incidence of post caesarean laparotomy and identify the risk factors, indications and management.

Methods: We conducted a retrospective observational study in a tertiary care hospital in North Kerala from January 1, 2011 to December 31, 2014 of the twenty seven cases which required relaparotomy following caesarean section.

Results: In our study there were a total of 20928 caesarean deliveries and 27 cases required exploratory laparotomy following caesarean section. Majority of the cases were following emergency caesarean section, 23 cases $(85.19 \%)$. The most common indication for the caesarean section was failure to progress in labour in 8 cases $(29.63 \%)$. Relaparotomy was done within 24 hours after caesarean in 23 cases (85.19\%). Regarding the indication of relaparotomy, 5 cases were due to atonic postpartum hemorrhage $(18.52 \%)$ and 4 cases $(14.81 \%)$ due to traumatic PPH. Intraperitoneal hemorrhage was seen in 12 cases (44.44\%). Hysterectomy was required in a total of 21 cases (77.78\%), of which 14 had total hysterectomy $(66.67 \%)$. Third laparotomy following the relaparotomy was required in one case. Regarding postoperative complications, 8 cases $(29.63 \%)$ required mechanical ventilation and 4 cases $(14.81 \%)$ developed multiorgan failure. There were 5 cases of maternal death $(18.52 \%)$.

Conclusions: Decision to proceed for early reoperation after caesarean section is a real challenge. Indication of the primary surgery, patient's preoperative condition and indication for relaparotomy will influence the outcome. Assuring meticulous hemostasis before closure is very important, as postpartum hemorrhage was the most common indication for relaparotomy. It is also important that relaparotomy should be done in centres with efficient blood transfusion facilities in order to reduce the morbidity and mortality.

Keywords: Caesarean section, Postoperative, Relaparotomy

\section{INTRODUCTION}

Caesarean section is the most common obstetric operation done in daily obstetric practice. There is a dramatic increase in caesarean section rates in many countries over the past several decades. ${ }^{1}$ The safety of caesarean section has increased considerably with the improvement of surgical techniques, aseptic techniques, anaesthesia and facilities for blood transfusion. The increase in caesarean section may be explained by the improved fetal monitoring techniques and better surgical facilities. Complications following caesarean section are higher than that of vaginal delivery. ${ }^{3}$ This depends on the surgical technique, institutional facilities and also the indication of surgery. Relaparotomy following caesarean section is considered in the event of a near miss maternal mortality. ${ }^{4}$ Usually it is performed when the condition of the patient is too critical to withstand the risk of anaesthesia and repeat operation. The decision requires a good clinical judgement and it is the last resort to save a mother's life. The common indications of relaparotomy 
following caesarean section include postpartum hemorrhage, intraperitoneal hemorrhage, sepiticemia, burst abdomen, rectus sheath hematoma etc. Studies on relaparotomy following caesarean section are very little.? Hence our study aims to find out the risk factors, maternal morbidity and mortality associated with relaparotomy after caesarean section.

\section{METHODS}

This was a retrospective descriptive study conducted in the department of Obstetrics and Gynaecology, Institute of Maternal and Child Health, Government Medical College, Kozhikode over a period of 4 years from January 1, 2011 to December 31, 2014. During this period relaparoromy was done in 27 cases following caesarean section.

\section{RESULTS}

Over a period of 4 years from January 1, 2011 to December 31, 2014 there were a total of 20928 caesarean deliveries and 27 cases required exploratory laparotomy following caesarean section. 25 cases were in the age group of 20 to 35 years $(92.6 \%)$ and only one case was above 35 years old. 9 cases were primipara (33.3\%), 16 were of parity 2 to $4(59.26 \%)$ and 2 cases of parity 5 and above $(7.4 \%)$ (Table 1$)$.

Table 1: Demographic variables.

\begin{tabular}{|lll|}
\hline \multicolumn{3}{|c|}{ Number } \\
\hline Age (years) \\
\hline$<20$ & 1 & $3.7 \%$ \\
\hline $20-35$ & 25 & $92.6 \%$ \\
\hline$>35$ & 1 & $3.7 \%$ \\
\hline Parity & & \\
\hline 1 & 9 & $33.33 \%$ \\
\hline $2-4$ & 16 & $59.26 \%$ \\
\hline$\geq 5$ & 2 & $7.4 \%$ \\
\hline
\end{tabular}

In 18 cases $(66.67 \%)$ caesarean section was done in our institution where as 9 cases $(33.33 \%)$ were referred from other hospitals after caesarean section. 23 cases $(85.19 \%)$ out of the total 27 cases had emergency caesarean section and $4(14.81 \%)$ were following elective caesarean section. Of the total 27 cases 14 were primary caesarean section $(51.9 \%)$ and 13 cases $(48.15 \%)$ were repeat caesarean sections (Table 2). Caesarean section was done between $10 \mathrm{pm}$ and 6 am in 6 cases $(22.2 \%)$ whereas 21 cases $(77.8 \%)$ were done between 6 am and $10 \mathrm{pm}$. The duration of primary caesarean section was more than 1 hour in only 5 cases $(18.52 \%)$. In 22 cases the caesarean section duration was 1 hour or less $(81.48 \%$ ) (Table 3 ). The most common indication for the caesarean section was failure to progress in labour, 8 cases (29.63\%). Other indications for caesarean section were fetal distress in 6 cases $(22.2 \%)$, post caesarean section in 6 cases $(22.2 \%)$, placenta previa in $4(14.81 \%)$, failed induction in 2
(7.4\%) and abruption in 1 case (3.7\%) (Table 4). Relaparotomy was done within 24 hours after caesarean in 23 cases $(85.19 \%)$. Only 3 cases underwent resurgery between 24 hours and 7 days after caesarean section $(11.11 \%)$. 1 case $(3.7 \%)$ of relaparotomy was done more than 1 month after caesarean section, which was the case of uterine necrosis, which followed B Lynch suture for postpartum haemorrhage (Table 5).

Table 2: Details of caesarean section.

\begin{tabular}{|lll|}
\hline \multicolumn{2}{|c|}{ Number } & Percentage \\
\hline Elective CS & 4 & $14.81 \%$ \\
\hline Emergency CS & 23 & $85.19 \%$ \\
\hline Primary CS & 14 & $51.9 \%$ \\
\hline Repeat CS & 13 & $48.15 \%$ \\
\hline Place of CS & & \\
\hline IMCH & 18 & $66.67 \%$ \\
\hline Referred & 9 & $33.33 \%$ \\
\hline
\end{tabular}

Table 3: Time of performing and duration of caesarean section.

\begin{tabular}{|l|l|}
\multicolumn{3}{|c|}{ Number } \\
\hline Time of performing CS \\
\hline 10 pm to 6 am 6 & $22.22 \%$ \\
\hline 6 am to $10 \mathrm{pm} \quad 21$ & $77.8 \%$ \\
\hline Duration of CS \\
\hline$>1$ hour $\quad 5$ & $18.52 \%$ \\
\hline$\leq 1$ hour $\quad 22$ & $81.48 \%$ \\
\hline
\end{tabular}

Table 4: Indications of CS.

\begin{tabular}{|lll|}
\hline & Number & Percentage \\
\hline Failure to progress & 8 & $29.63 \%$ \\
\hline Fetal distress & 6 & $22.22 \%$ \\
\hline Post caesarean section & 6 & $22.22 \%$ \\
\hline Placenta previa & 4 & $14.81 \%$ \\
\hline Abruption & 1 & $3.7 \%$ \\
\hline Failed induction & 2 & $7.4 \%$ \\
\hline
\end{tabular}

Table 5: Time interval between CS and relaparotomy.

\begin{tabular}{|lll|}
\hline & Number & Percentage \\
\hline$<24$ hours & 23 & $85.19 \%$ \\
\hline 24 hours to 7 days & 3 & $11.11 \%$ \\
\hline$>1$ month & 1 & $3.7 \%$ \\
\hline
\end{tabular}

Regarding the indication of relaparotomy, 5 cases were due to atonic postpartum haemorrhage $(18.52 \%), 4$ cases $(14.81 \%)$ due to traumatic $\mathrm{PPH}, 12$ cases due to intraperitoneal haemorrhage $(44.44 \%)$. 2 cases due to rectus sheath hematoma and 2 cases due to broad ligament haematoma. One case each of uterine necrosis and bowel ischemia was present (Table 6). 
Table 6: Indication of relaparotomy.

\begin{tabular}{|llll|}
\hline \multirow{2}{*}{ PPH } & \multicolumn{1}{c}{ Number } & Percentage \\
\cline { 2 - 4 } & Atonic & 5 & $18.52 \%$ \\
\hline Rectus sheath hematoma & 4 & $14.81 \%$ \\
\hline Intraperitoneal hemorrhage & 12 & $7.4 \%$ \\
\hline Broad ligament hematoma & 2 & $44.44 \%$ \\
\hline Uterine necrosis & 1 & $7.4 \%$ \\
\hline Bowel ischemia & 1 & $3.7 \%$ \\
\hline
\end{tabular}

Findings at relaparotomy were atonic PPH in 7 cases $(25.93 \%)$, traumatic PPH $(3.7 \%)$ and both atonic and traumatic $\mathrm{PPH}$ in 4 cases $(14.81 \%)$. Intraperitoneal hemorrhage was seen associated with atonic $\mathrm{PPH}$ in 2 cases, with both atonic and traumatic PPH in 4 cases, bleeding from the endometrial deposits in 2 cases, bleeding from the tubal sterilization site in 2 cases, rectus sheath haematoma in 2 cases and broad ligament haematoma in 2 cases and disseminated intravascular coagulation in one case. Retroperitoneal hematoma was present in one case, bowel gangrene in one case and uterine necrosis in one case (Table 7).

Table 7: Intraoperative findings.

\begin{tabular}{|llll|}
\hline \multirow{2}{*}{ Atonic PPH } & & Number & Percentage \\
\hline Traumatic PPH & 7 & $25.93 \%$ \\
\hline Both atonic \& traumatic PPH & 1 & $3.7 \%$ \\
\hline & Atonic PPH & 2 & $14.82 \%$ \\
\cline { 2 - 4 } & $\begin{array}{l}\text { Atonic PPh }+ \\
\text { Traumatic PPH }\end{array}$ & 1 & $7.4 \%$ \\
\cline { 2 - 4 } & $\begin{array}{l}\text { Endometrial } \\
\text { deposits bleeding }\end{array}$ & 2 & $3.7 \%$ \\
\cline { 2 - 4 } $\begin{array}{l}\text { Intraperitoneal } \\
\text { hemorrhage } \\
\text { associated } \\
\text { with }\end{array}$ & $\begin{array}{l}\text { Sterilization site } \\
\text { bleeding }\end{array}$ & 2 & $7.4 \%$ \\
\cline { 2 - 4 } & $\begin{array}{l}\text { Rectus sheath } \\
\text { haematoma }\end{array}$ & 2 & $7.4 \%$ \\
\cline { 2 - 4 } & $\begin{array}{l}\text { Broad ligament } \\
\text { haematoma }\end{array}$ & 2 & $7.4 \%$ \\
\cline { 2 - 4 } & DIC & 1 & $3.7 \%$ \\
\hline Retroperitoneal haematoma & 1 & $3.7 \%$ \\
\hline Bowel gangrene & 1 & $3.7 \%$ \\
\hline Uterine necrosis & & 1 & \\
\hline
\end{tabular}

Hysterectomy was required in a total of 21 cases $(77.78 \%)$, of which 14 had total hysterectomy $(66.67 \%)$ and $7(33.33 \%)$ had subtotal hysterectomy. Ligation of bleeding vessels alone was required in 2 cases. Ligation of tubal sterilization site bleeding vessel was done in 2 cases. Hysterectomy with exploration of subrectus haematoma and ligation of bleeding vessels were done in 2 cases. Hysterectomy with ligation of internal iliac artery was done in 9 cases. Hysterectomy with ligation of bleeding vessels was done in 4 cases. B Lynch sutures with ligation of uterine and ovarian vessels were done in one case. B Lynch sutures with ligation of uterine and ovarian vessels and exploration of subrectus haematoma and ligation of bleeding vessels was done in one case. B Lynch sutures with internal iliac artery ligation were done in one case. Limited ileocolectomy was done in one case. This was a case of valve replacement who developed thromboembolism and the resultant bowel ischemia (Table 8).

Table 8: Procedures performed at relaparotomy.

\begin{tabular}{|lll|}
\hline \multicolumn{1}{|l}{ Ligation of bleeding vessels } & 2 & $7.4 \%$ \\
\hline $\begin{array}{l}\text { Ligation of tubal sterilization } \\
\text { site bleeder }\end{array}$ & 2 & $7.4 \%$ \\
\hline $\begin{array}{l}\text { Hysterectomy + exploration } \\
\text { of subrectus haematoma, } \\
\text { ligation of vessels }\end{array}$ & 2 & $7.4 \%$ \\
\hline $\begin{array}{l}\text { Hysterectomy + internal iliac } \\
\text { artery ligation }\end{array}$ & 9 & $33.33 \%$ \\
\hline $\begin{array}{l}\text { Hysterectomy + ligation of } \\
\text { bleeding vessels }\end{array}$ & 4 & $14.81 \%$ \\
\hline $\begin{array}{l}\text { B Lynch sutures + ligation of } \\
\text { bilateral uterine \& ovarian } \\
\text { vessels }\end{array}$ & 1 & $3.7 \%$ \\
\hline $\begin{array}{l}\text { B Lynch sutures + ligation of } \\
\text { bilateral uterine \& ovarian } \\
\text { vessels + Exploration of } \\
\text { subrectus hematoma }+ \\
\text { ligation of bleeding vessels }\end{array}$ & 1 & $3.7 \%$ \\
\hline $\begin{array}{l}\text { B Lynch sutures+ internal } \\
\text { iliac artey ligation }\end{array}$ & 1 & $3.7 \%$ \\
\hline Limited ileocolectomy & 1 & $3.7 \%$ \\
\hline
\end{tabular}

Third laparotomy following the relaparotomy was required in one case. Here relaparotomy and total hysterectomy was done due to atonic postpartum hemorrhage. Suspecting hemoperitoneum, a third laparotomy was done and there was bleeding from the infunibulopelvic ligament which was ligated. Majority of the cases did not have intraoperative complications. 1 case each had bladder injury and ureteric injury. 1 patient had pulmonary edema.

Regarding postoperative complications, 8 cases (29.63\%) required mechanical ventilation and 4 cases $(14.81 \%)$ developed multiorgan failure. 5 cases $(18.52 \%)$ had febrile morbidity, 2 cases developed parietal haematoma, 1 case each developed sepsis and seizures (Table 9).

Table 9: Postoperative complications.

\begin{tabular}{|lll|}
\hline & Number & Percentage \\
\hline Mechanical ventilation & 8 & $29.63 \%$ \\
\hline Parietal haematoma & 2 & $7.4 \%$ \\
\hline Febrile morbidity & 5 & $18.52 \%$ \\
\hline Seizures & 1 & $3.7 \%$ \\
\hline Sepsis & 1 & $3.7 \%$ \\
\hline MODS & 4 & $14.81 \%$ \\
\hline
\end{tabular}


There were 5 cases of maternal death (18.52\%). In 4 of them, at relaparotomy there was intraperitoneal hemorrhage. Of this 2 cases had both atonic and traumatic PPH, 1 case had only atonic PPH and another case with only traumatic PPH. Of these three cases, the relaparotomy was done within 5 hours after caesarean section. The fifth case of maternal death had bowel gangrene, limited ileocolectomy was done and developed septicemia in the postoperative period.

\section{DISCUSSION}

Caesarean section is a major abdominal operation with it's attendant complications to the mother including hemorrhage, infection and injury to other organs. In day to day obstetric practice we have to deal with postcaesarean complications associated with maternal morbidity and mortality. During our study period, there were a total of 20928 caesarean deliveries and 27 cases required laparotomy following caesarean section $(0.13 \%)$. The rate of relaparotomy after caesarean was $0.2 \%$ in study by Levin et al. ${ }^{1}$ In study by Shiri Shinar $0.4 \%$ cases required relaparotomy. ${ }^{2}$ In study by Raagab $\mathrm{AE}$, incidence was $1.04 \% .^{3}$ The rate of relaparotomy following caesarean section in our study was comparable to the other studies quoted. The incidence of relaparotomy was $0.12 \%$ in study by Gedikbasi.

Most of our cases $(92.6 \%)$ were in the age group of 20 to 35 years and only one case was above 35 years old. Majority of our pregnant patients belonged to the age group of 20 to 35 years. In a study by Biswas SP, the ages of the patient were between 15 and 35 years with a mean of 25 years. ${ }^{4}$

$59 \%$ were para 2 to para $4,7.4 \%$ were para 5 and above, whereas only $33.3 \%$ were primipara. The risk of relaparotomty was found to be more with increasing parity.

Of the total 27 cases, 23 cases $(85.18 \%)$ had emergency caesarean section and only $4(14.8 \%)$ had elective caesarean section. Emergency caesarean section is an important risk factor for relaparotomy. In study by Seal SL, 95.5\% had emergency caesarean and 4.55 had elective caesarean section..$^{5}$ In study by Raagab AE, $95.5 \%$ had emergency caesarean delivery. ${ }^{3}$ In our study $51.85 \%$ were primary caesarean sections and $48.15 \%$ were repeat caesarean sections.

Regarding the time of performing caesarean section, only $22.22 \%$ were done between $10 \mathrm{pm}$ and 6 am. Majority $(77.8 \%)$ were done during day time. Only in 5 cases $(18.52 \%)$, the duration of caesarean section was more than 1 hour. In study by Levin, there was significant difference between the study and the control group in the duration of primary operation, 45.3 minutes vs. 29.9 minutes. ${ }^{1}$

The most common indication of caesarean section was failure to progress in labour $(29.6 \%)$. Other indications were fetal distress (22.2\%), previous CS (22.2\%) and placenta previa (14.8\%). In the study by Biswas SP, the commonest indication of primary caesarean section was prolonged labour and fetal distress in $40 \%{ }^{4}$

23 cases $(85.18 \%)$ had relaparotomy within 24 hours after caesarean section. Only 3 cases $(11.11 \%)$ underwent resurgery between 24 hours and 7 days after caesarean section. Hence close observation of cases within 24 hours following caesarean section is very important especially the vital signs, uterine contractility and both vaginal bleeding and intraperitoneal bleeding. In study by Levin et al relaparotomy was done an average of 5 hours after the first surgery. In study by Biswas SP, $32.73 \%$ cases were done within $7^{\text {th }}$ postoperative day. ${ }^{4}$ In study by Raagab AE, relaparotomy was performed within 5.5 hours after the primary procedure. ${ }^{3}$ In study by Kessous $\mathrm{R}, 51.2 \%$ underwent relaparotomy within 24 hours after caesarean section. ${ }^{6}$

As far as the indication of repeat surgery is concerned, 9 cases were due to postpartum hemorrhage, 12 cases due to intraperitoneal hemorrhage. 2 cases had rectus sheath hematoma and 2 cases had broad ligament haematoma .It is consistent with the results from the previous studies. In study by Levin et al., the main indication for relaparotomy was hemodynamic instability due to suspected intra-abdominal bleeding or uncontrolled PPH. ${ }^{1}$ PPH was the commonest reason for relaparotomy in study by Biswas SP. ${ }^{4}$ In study by Seal SL, PPH in $42.4 \%$ and rectus sheath hematoma in $27.3 \%$ cases were the leading indications for relaparoromy. ${ }^{5}$ These findings demand special attention to effectively manage primary PPH as well as secondary PPH. Bleeding secondary to uterine atony is preventable by adopting active management of third stage of labour. In the study by Ashwal, PPH was the leading indication of relaparotomy. ${ }^{12}$

Findings at relaparotomy were atonic PPH in 7 cases, traumatic PPH and both atonic and traumatic PPH in 4 cases. Intraperitoneal hemorrhage was seen associated with atonic PPH in 2 cases, with both atonic and traumatic PPH in one case, bleeding from the endometrial deposits in 2 cases, bleeding from the tubal sterilization site in 2 cases, rectus sheath haematoma in 2 cases and broad ligament haematoma in 2 cases and disseminated intravascular coagulation in one case. Retroperitoneal hematoma was present in one case, bowel gangrene in one case and uterine necrosis in one case. In the study by Shyamal D, intraperitoneal hemorrhage was found in $48.93 \% .^{7}$ Hemorrhage was common and a leading cause where early relaparotomies were required as reported by different studies. Safe method of suturing the lower uterine segment incision at caesarean section and care during transverse cutting and suturing of lateral extension of rectus sheath are described as procedures to reduce postoperative complications. In the study by Shinar S, the leading indications for relaparotomy were hemodynamic shock and subcutaneous hematoma. ${ }^{2}$ 
Hysterectomy was required in a total of 21 cases (77.78\%), of which 14 had total hysterectomy $(66.66 \%)$ and $7(33.33 \%)$ had subtotal hysterectomy. In a study by Lurie, only one case required hysterectomy among the eighteen cases studied. ${ }^{11}$

Ligation of bleeding vessels alone was required in 2 cases. Ligation of tubal sterilization site was done in 2 cases. Hysterectomy with exploration of subrectus haematoma and ligation of bleeding vessels were done in 2 cases. Hysterectomy with ligation of internal iliac artery was done in 9 cases. Hysterectomy with ligation of bleeding vessels was done in 4 cases. B Lynch sutures with ligation of uterine and ovarian vessels were done in one case. B Lynch sutures with ligation of uterine and ovarian vessels and exploration of subrectus haenmatoma and ligation of bleeding vessels was done in one case. B Lynch sutures with internal iliac artery ligation were done in one case. Limited ileocolectomy was done in one case. In the study by Gedikbasi, procedures done at relaparotomy were drainage and resuturing of haematoma and resuturing of uterus, bladder repair, total and subtotal hysterectomy etc. ${ }^{9}$ In the study by Seffah, main surgeries done were hysterectomy, internal iliac artery ligation, debridement and resuturing of uterine incision and secondary suturing of anterior abdominal wall. ${ }^{10}$

In study by Biswas SP, hysterectomy or subtotal hysterectomy was done in $38.18 \%$ and conservative surgery was done in $61.82 \% .{ }^{4}$ Conservative surgery included Brace sutures, ligation of uterine and ovarian vessels, removal of subrectus hematoma etc. In study by Kessous Roy, hysterectomy was performed in $31.3 \%$ patients. ${ }^{6}$ In the study by Shinar S, the most common interventions during relaparotomy were cauterization of subcutaneous vessels and ligation of large vessels. ${ }^{2}$

Majority of the cases did not have intraoperative complications. One case each had bladder injury and ureteric injury and one patient developed pulmonary edema.

Regarding postoperative complications, 4 cases (14.81\%) developed multiorgan failure and 8 cases $(29.63 \%)$ required mechanical ventilation. 5 cases $(18.52 \%)$ had febrile morbidity, 2 cases developed parietal haematoma, 1 case each developed sepsis and seizures.

Third laparotomy was required in only one case $(3.7 \%)$. In study by Seal SL, third laparotomy was required in $19.6 \% .^{5}$ Here relaparotomy and total hysterectomy was done due to atonic postpartum hemorrhage. Suspecting hemoperitoneum, a third laparotomy was done and there was bleeding from the infunibulopelvic ligament which was ligated.

There were 5 cases of maternal death (18.52\%). In 4 of them, at relaparotomy there was intraperitoneal hemorrhage. Of this 2 cases had both atonic and traumatic PPH, 1 case had only atonic PPH and another case with only traumatic PPH. Of this three cases, the relaparotomy was done within 5 hours after caesarean section. The fifth case of maternal death had bowel gangrene, limited ileocolectomy was done and developed septicemia in the postoperative period. In a study by Shyamal D, maternal death was $15.38 \%$, similar to our study. ${ }^{7}$ In the study by Seffah, case fatality rate for relaparotomy after caesarean section is high at $9 \% .^{10}$

Caesarean section is the most common life-saving obstetric operation. Relaparotomy is done as a procedure in cases of near miss fatality of mother. Since hemorrhage was the most important indication of relaparotomy, close monitoring of patients within the first 24 hours after caesarean section should be followed meticulously. Every effort must be made to make the procedure safe. If personnel and adequate blood components are available, relaparotomy should not be delayed for the management of intractable hemorrhage and unstable vital signs after caesarean section. ${ }^{8}$

\section{ACKNOWLEDGEMENTS}

We acknowledge all the staff and residents involved in the care of these patients.

\section{Funding: No funding sources \\ Conflict of interest: None declared \\ Ethical approval: Not required}

\section{REFERENCES}

1. Levin I, Rapaport AS, Satzor L, Maslovitz S, Lessing JB, Almog B. Risk factors for relaparotomy after caesarean delivery. Int J Gynaecol Obstet. 2012;119:163-5.

2. Shinar S, Hareuveni M, Ben-Tal O, Many A. Relaparotomies after caesarean sections: risk factors, indications and management. J Perinatal Med. 2013;41:567-72.

3. Raagab AE, Misbah YH, Brabat RI, Zayed AA, Alsaammani MA. Relaparotomy after caesarean section: risks, indications and management options. Med Arch. 2014;68:44-5.

4. Biswas SP, Halder S, Shirin FB. Indications and outcome of relaparotomy after caesarean section. Bang Med J. 2012;45:19-23.

5. Seal SL, Kamilya G, Bhattacharyya SK, Mukherji J, Bhattarcharyya AR. Relaparotomy after caesarean delivery: experience from an Indian Teaching Hospital. J Obstet Gynaecol Res. 2007;33(6):804-9.

6. Kessous R, Danor D, Weintraub A, Wiznitzer A, Sergienko R, Ohel I, et al. Risk factors for relaparotomy after caesarean section. J MaternalFetal Neonatal Med. 2012;25:2167-70.

7. Shyamal D, Pratim SP, Aradhana K, Partha M, Kirti M, Subhankar D. Early re-operations after gynecological and obstetrical surgery-a five years. J Obstet Gynecol India. 2010;60:507-10.

8. Park CE, Sung JE, Kyung MS, Cho Y, Ro ES. A clinical analysis of 10 cases of relaparotomy after 
emergency postpartum hysterectomy. Korean J Obstet Gynecol. 2010;53:313-22.

9. Gedikbasi A, Akyol A, Asar E, Bingol B, Uncu R, Sargin A, et al. Relaparotomy after cesarean section: operative complications in surgical delivery. Arch Gynecol Obstet. 2008;278(5):419-25.

10. Seffah JD. Relaparotomy after cesarean section. Int J Gynaecol Obstet. 2005;88(3):253-7.

11. Lurie S, Sadan O, Golan A. Realaparotomy after cesarean section. Eur J Obstet Gynecol Reprod Biol. 2007;134(2):184-7.
12. Ashwal E, Yogev Y, Melamed N, Khadega R, Ben Haroush A, Wiznitzer A, et al. Characterizing the need for relaparotomy during puerperium after cesarean section. Arch Gynecol Obstet. 2014;290(1):35-9.

DOI: $10.18203 / 2320-1770 . i j \operatorname{rog} 20150054$

Cite this article as: Ahmed Khan NB, Kolasseri SS.

Relaparotomy after caesarean section: an analysis of the risk factors, indications and outcome. Int $\mathbf{J}$

Reprod Contracept Obstet Gynecol 2015;4:575-80. 